\title{
Cobalamin-dependent 1,2-propanediol utilization by Salmonella typhimurium
}

\author{
RANDAll M. JETER \\ Department of Biological Sciences, Texas Tech University, Lubbock, Texas 79409-3131, USA
}

(Received 23 October 1989; revised 5 January 1990; accepted 18 January 1990)

\begin{abstract}
The enteric bacterium Salmonella typhimurium utilizes 1,2-propanediol as a sole carbon and energy source during aerobic growth, but only when the cells are also provided with cobalamin as a nutritional supplement. This metabolism is mediated by the cobalamin-dependent propanediol dehydratase enzyme pathway. Thirty-three insertion mutants were isolated that lacked the ability to utilize propanediol, but retained the ability to degrade propionate. This phenotype is consistent with specific blocks in one or more steps of the propanediol dehydratase pathway. Enzyme assays confirmed that propanediol dehydratase activity was absent in some of the mutants. Thus, the affected genes were designated $p d u$ (for defects in propanediol utilization). Seventeen mutants carried $p d u$ :: lac operon fusions, and these fusions were induced by propanediol in the culture medium. All of the pdu mutations were located in a single region (41 map units) on the $S$. typhimurium chromosome between the his (histidine biosynthesis) and branch I cob (cobalamin biosynthesis) operons. They were shown to be P22cotransducible with a branch I cob marker at a mean frequency of $12 \%$. Mutants that carried deletions of the genetic material between $h i s$ and $c o b$ also failed to utilize propanediol as a sole carbon source. Based upon the formation of duplications and deletions between different pairs of $h i s:$ :MudA and pdu:: MudA insertions, the pdu genes were transcribed in a clockwise direction relative to the $S$. typhimurium genetic map.
\end{abstract}

\section{Introduction}

Salmonella typhimurium synthesizes cobalamin (vitamin $\mathrm{B}_{12}$ ) de novo, but only during anaerobic growth (Jeter $e t$ al., 1984). This enteric bacterium makes a substantial genetic commitment to produce cobalamin: an estimated 20 to 30 enzymes are uniquely employed for its synthesis (Jeter \& Roth, 1987). The genes that encode the cobalamin biosynthetic enzymes are clustered at 41 map units on the $S$. typhimurium chromosome. These genes (designated $c o b$ ) are organized into three operons that generally correspond to the biochemical functions of their gene products. The branch I cob operon is responsible for the synthesis of the corrinoid intermediate cobinamide, the branch II cob operon for the synthesis of 5,6-dimethylbenzimidazole, and the branch III $c o b$ operon for the incorporation of these components into the complete cobalamin molecule (Jeter et al., 1987; Jeter \& Roth, 1987).

The importance of cobalamin to the general metabolism of $S$. typhimurium remains poorly understood. Until recently, only two cobalamin-dependent enzymes were known to occur in S. typhimurium. Tetrahydropteroylglutamate-homocysteine methyltransferase
(EC 2.1.1.13) catalyses the transfer of a methyl group from $N^{5}$-methyltetrahydrofolate to L-homocysteine, yielding L-methionine as a product (Cauthen et al., 1966). This enzyme is encoded by the met $H$ gene (Childs \& Smith, 1969). However, $S$. typhimurium possesses a second enzyme (encoded by the met $E$ gene) that catalyses the same reaction but does not require cobalamin for activity (Smith, 1961). Thus, cobalamin normally does not need to be available in order for the cells to carry out this last step in methionine biosynthesis. Ethanolamine ammonia-lyase (EC 4.3.1:7) catalyses the cleavage of ethanolamine to acetaldehyde and ammonia. In the presence of exogenously supplied cobalamin, this enzyme allows $S$. typhimurium to use ethanolamine as a sole source of carbon and energy for aerobic growth (Chang \& Chang, 1975; Roof \& Roth, 1988).

A third enzymic function that requires cobalamin has been identified recently in $S$. typhimurium: the reduction of epoxyqueuosine to queuosine (Frey et al., 1988). Queuosine is a modified nucleoside that replaces guanosine in the anticodons of certain transfer RNA (tRNA) molecules (Björk, 1987; Björk et al., 1987). In the absence of exogenously supplied cobalamin, anaerobically grown $S$. typhimurium produces tRNAs that contain 
primarily queuosine, whereas aerobically grown $S$. typhimurium produces tRNAs that contain only the precursor epoxyqueuosine (Frey et al., 1988).

Propanediol dehydratase (EC 4.2.1.28) is another cobalamin-dependent enzyme that is found in certain genera of the enteric bacteria (e.g. Klebsiella) but not in others (e.g. Escherichia). This enzyme, which catalyses the removal of water from 1,2-propanediol to yield propionaldehyde, has been purified from $K$. pneumoniae and its reaction mechanism has been characterized extensively (Abeles \& Lee, 1961; Lee \& Abeles, 1963; Toraya et al., 1977). Propanediol dehydratase catalyses the first step in an anaerobic pathway that converts 1,2propanediol into equimolar amounts of 1-propanol and propionate (Toraya et al., 1979). Both products are excreted into the culture medium. Thus, propanediol does not serve as a sole carbon source for anaerobic growth (Forage \& Foster, 1982). Instead, the enzyme pathway appears to operate for the generation of additional ATP by substrate-level phosphorylation (Toraya et al., 1979). This pathway has been detected recently in anaerobically grown cultures of $S$. typhimurium (Obradors et al., 1988). Thus, propanediol dehydratase represents a fourth cobalamin-dependent function that occurs in S. typhimurium.

In this paper, I report that $S$. typhimurium is also able to grow aerobically by utilizing 1,2-propanediol as a sole source of carbon and energy. However, this growth occurs only when cobalamin is present in the culture medium as a nutritional supplement. I describe the isolation and genetic characterization of mutants that are defective in the utilization of 1,2-propanediol. All of these mutations are located in a single region (41 map units) on the $S$. typhimurium chromosome and they lie close to the $c o b$ genes.

\section{Methods}

Bacterial and bacteriophage strains. The genotypes of the bacterial strains that were used in this study are given in Table 1. All of the strains were derived from $S$. typhimurium LT2. The bacteriophage that was used in all transductional crosses was P22 HT 105/1 int-201. This derivative of bacteriophage $\mathbf{P} 22$ performs generalized transduction at higher frequencies (75-fold and above) than wild-type P22 and is defective for integration into the bacterial chromosome (Anderson \& Roth, 1978; Schmieger, 1971, 1972). MudA is a conditionally transposition-deficient derivative of the Mudl (Amp, Lac) bacteriophage of Casadaban \& Cohen (1979). MudA does not transpose except in host cells that also carry an amber (nonsense) suppressor mutation (Hughes \& Roth, 1984). MudJ is the MudII1734 derivative that was originally isolated by Castilho et al. (1984). Since MudJ carries a deletion that includes the $\mathrm{A}$ and $\mathrm{B}$ genes of $\mathrm{Mu}$, a separate genetic element must provide the missing transposition functions by complementation (Hughes \& Roth, 1988). MudA and MudJ carry resistance determinants to the antibiotics ampicillin and kanamycin, respectively.
Culture media and growth conditions. Nutrient broth $\left(8 \mathrm{~g}^{-1}\right.$, Difco) with the addition of $\mathrm{NaCl}\left(5 \mathrm{~g} \mathrm{1}^{-1}\right)$ was used as the complex medium for the routine cultivation of bacterial strains. The $\mathrm{E}$ medium of Vogel \& Bonner (1956) with the addition of D-glucose $(14 \mathrm{mM})$ as a carbon source was generally used as the minimal medium. NCE (no carbon E) minimal medium base (Davis et al., 1980) was substituted when the cells were utilizing carbon sources other than glucose. Alternative carbon sources included DL-1,2-propanediol, propionate and ethanolamine (all $26 \mathrm{mM}$ ). Nutritional supplements were added as required to meet the needs of individual strains. The final concentrations of amino acids, purines and pyrimidines in the medium were 0.1 to $0.5 \mathrm{mM}$ (as specified in Davis et al., 1980); the final concentration of cyanocobalamin was $15 \mathrm{nM}$. Antibiotics were added to the following final concentrations in minimal and complex media, respectively: kanamycin sulphate, 125 or $50 \mathrm{mg} \mathrm{l}^{-1}$; sodium ampicillin, 15 or $30 \mathrm{mg} \mathrm{l}^{-1}$; and tetracycline hydrochloride, 10 or $20 \mathrm{mg} \mathrm{l}^{-1}$. Solid medium contained agar $\left(15 \mathrm{~g} \mathrm{l}^{-1}\right.$, Difco). Organic chemicals and biochemicals were supplied by Aldrich, Boehringer Mannheim and Sigma. Inorganic chemicals were supplied by J. T. Baker Chemicals and Fisher Scientific.

Unless otherwise specified, all cultures were grown at $37^{\circ} \mathrm{C}$. Aerobic liquid cultures were grown in an incubator rotary shaker (model G25, New Brunswick Scientific) at 200 r.p.m.

Growth measurements. S. typhimurium LT2 was grown at $30^{\circ} \mathrm{C}$ in two $500 \mathrm{ml}$ culture flasks that contained $150 \mathrm{ml}$ of NCE minimal medium with propanediol as the sole carbon and energy source. Cobalamin was added as a nutritional supplement to one of the cultures. At regular intervals, samples were taken and the cell densities were measured as the optical density at $540 \mathrm{~nm}$. Readings were taken with a Spectronic 21 spectrophotometer (Bausch and Lomb)

Transductional methods. Bacteriophage P22 lysates were prepared on donor strains of $S$. typhimurium by using the rapid procedure of Davis $e t$ al. (1980). The methods that were used for the transduction of recipient cells, and the selection and purification of transductant colonies with the desired phenotypes, have been described previously (Jeter \& Roth, 1987). Phage-free transductants were isolated by streaking nonselectively onto modified green indicator plates to obtain light-coloured colonies (Smith \& Levine, 1967). The modified medium contains a reduced concentration of aniline blue $\left(80 \mathrm{mg} \mathrm{l}^{-1}\right)$ and alizarin yellow is replaced by fluorescein (uranine; $30 \mathrm{mg} \mathrm{l}^{-1}$ ) as recommended by Bochner (1984)

Mutant isolation. MudA insertion strains were isolated by transducing a recipient strain (TT7610) that carried an amber (nonsense) suppressor mutation (supD501). The P22 lysate was grown on a donor strain that possessed an $\mathrm{F}^{\prime}$ plasmid carrying a MudA insertion (TT8388). The complete MudA element was introduced into the recipient cells as the consequence of a two-fragment transduction event and inherited solely by transposition into random chromosomal sites (Hughes \& Roth, 1984, 1985). Transductant colonies were selected at $30^{\circ} \mathrm{C}$ for ampicillin resistance and were then screened for loss of their ability to utilize propanediol as a sole carbon source. To stabilize the MudA insertions, P22 lysates were grown on confirmed mutants and the insertions were transduced into $S$. typhimurium LT2 (which is free of suppressor mutations). The donor DNA fragments carried both the MudA element and flanking $S$. typhimurium chromosomal sequences, and each MudA element was inherited by homologous recombination in these crosses.

Propanediol dehydratase assays. Strains were grown aerobically at $37^{\circ} \mathrm{C}$ in NCE succinate minimal medium with or without supplements of propanediol and cyanocobalamin. Cultures in maximum stationary phase were harvested by centrifugation $\left(5000 \mathrm{~g}\right.$ for $20 \mathrm{~min}$ at $\left.4^{\circ} \mathrm{C}\right)$, washed once, and resuspended in $70 \mathrm{~mm}$-potassium phosphate buffer, 
Table 1. S. typhimurium strains used in this study

\begin{tabular}{|c|c|c|}
\hline Strain $\dagger$ & Genotype & Reference or source \\
\hline $\begin{array}{l}\text { LT2 } \\
\text { TR6583 } \\
\text { TT627 } \\
\text { TT6195 } \\
\text { TT7610 } \\
\text { TT7691 } \\
\text { TT7692 } \\
\text { TT8388 } \\
\text { TT10441 } \\
\text { TT10927 } \\
\text { TT11073 } \\
\text { TT13787 } \\
\text { RT761 } \\
\text { RT762 } \\
\text { RT763 } \\
\text { RT764 } \\
\text { RT765 } \\
\text { RT766 } \\
\text { RT767 } \\
\text { RT785 } \\
\text { RT840 } \\
\text { RT841 } \\
\text { RT847 }\end{array}$ & 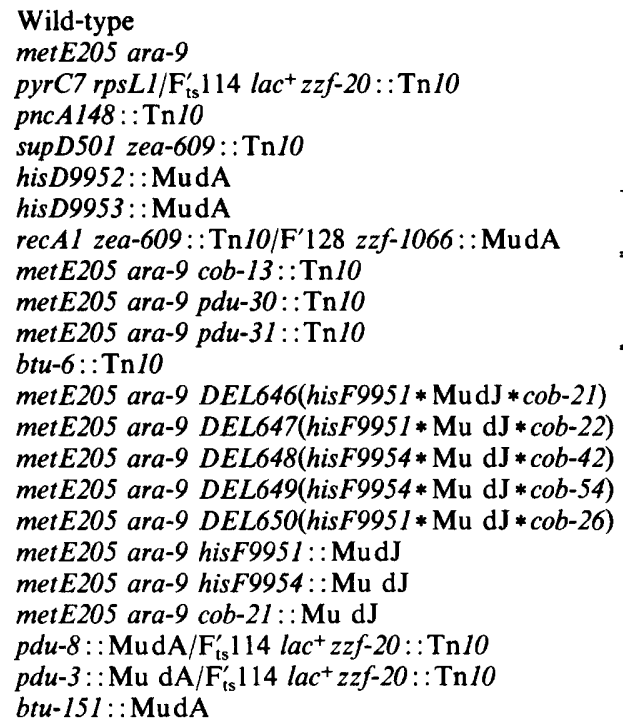 & $\begin{array}{l}\text { John Roth, University of Utah, USA } \\
\text { Jeter \& Roth (1987) } \\
\text { Chumley et al. (1979) } \\
\text { Hughes et al. (1983) } \\
\text { Hughes \& Roth (1984) } \\
\text { John Roth, University of Utah, USA } \\
\text { Hughes \& Roth (1984) } \\
\text { Jeter \& Roth (1987) }\end{array}$ \\
\hline
\end{tabular}

† Strains listed in Table 1 that are assigned TR or TT numbers were obtained from the culture collection of John Roth at the University of Utah, USA. Strains that are assigned RT numbers are in the author's culture collection.

$\ddagger D E L$ numbers are used for chromosomal rearrangements (deletions) that affect a series of genetic loci with different individual designations (Schmid \& Roth, 1983). The extent of each deletion is specified within the parentheses following the $D E L$ number. Asterisks (*) indicate that a transposable element is situated at the join point of the rearranged chromosomal sequences (Hughes \& Roth, 1985).

$\mathrm{pH} 8.0$ at a 10 -fold increase in cell concentration. Cells were then broken by ultrasonication (model TM-300 Sonic Disrupter; Tekmar Co.) at a power output of $200 \mathrm{~W}$. The crude extracts were shielded from light to avoid the degradation of adenosylcobalamin. Crude extracts were stored at $-70^{\circ} \mathrm{C}$ for up to 2 weeks before use, which did not impair the activity of the enzyme.

Propionaldehyde was measured by using the 3-methyl-2-benzothiazolinone hydrazone (MBTH) method (Paz et al., 1965; Sawicki et al., 1961; Soda, 1967). The enzyme assay procedure followed that described by Toraya et al. (1977). Assay tubes were protected from light during the enzyme reaction. The assay mixture contained $70 \mu \mathrm{mol}$ potassium phosphate buffer, pH $8 \cdot 0 ; 100 \mu \mathrm{mol} \mathrm{KCl} ; 30 \mathrm{nmol}$ adenosylcobalamin; $400 \mu \mathrm{mol} 1,2$-propanediol; and crude cell extract in a total volume of $2 \mathrm{ml}$. After incubation at $37^{\circ} \mathrm{C}$ for $30 \mathrm{~min}$, the reaction was terminated by the addition of $200 \mu \mathrm{mol}$ potassium citrate, $\mathrm{pH} 3 \cdot 6$, and $5 \mu \mathrm{mol}$ MBTH. After a second $30 \mathrm{~min}$ incubation, samples were taken and spun in a microcentrifuge $\left(16600 \mathrm{~g}\right.$ for $5 \mathrm{~min}$ at $\left.25^{\circ} \mathrm{C}\right)$ to remove cell debris. The absorbance of each supernatant was measured at $305 \mathrm{~nm}$ with an Acta CIII UV-Visible spectrophotometer (Beckman). The extinction coefficient at $305 \mathrm{~nm}$ was $14.7 \times 10^{3} \mathrm{I} \mathrm{mol}^{-1} \mathrm{~cm}^{-1}$. Propanediol dehydratase specific activity was defined as nmol propionaldehyde formed $\min ^{-1}$ (mg protein) $)^{-1}$.

The protein concentration in each crude extract was determined by using the bicinchoninic acid (BCA) procedure with BSA as the standard (Smith et al., 1985).

Conjugational methods. Hfr donor strains were created due to the integration of an $\mathrm{F}^{\prime}$ lac plasmid into chromosomal MudA insertions by homologous recombination between the lac sequences (Maloy \& Roth, 1983). The methods that were used were similar to those described by Chumley et al. (1979). The $\mathrm{F}_{\mathrm{is}}^{\prime} 114 \mathrm{lac}^{+}$plasmid was mated from strain
TT627 into two $p d u::$ MudA recipient strains (RT813 and RT818). Matings were done at $30^{\circ} \mathrm{C}$ by cross-streaking donor and recipient strains onto NCE lactose $(6 \mathrm{~mm})$ minimal medium plates. Only transconjugants grew on this medium, since the donor (TT627) also carried a mutational defect in pyrimidine biosynthesis, and the $p d u:: l a c$ fusions in the recipient cells were not expressed when propanediol was absent. $\mathrm{Lac}^{+}$transconjugants (RT840 and RT841) were purified, grown to full density at $30^{\circ} \mathrm{C}$ in NCE lactose minimal medium, and then streaked onto plates of the same medium for growth at $40^{\circ} \mathrm{C}$. $\mathrm{F}_{\mathrm{ts}}^{\prime} 114$ is temperature-sensitive for its own replication, and it is readily lost during cell growth at the high temperature unless it integrates into the chromosome. Under this circumstance, the plasmid is replicated passively as a part of the chromosome and the cells retain a $\mathrm{Lac}^{+}$phenotype (Jacob et al., 1963). Several large, healthy $\mathrm{Lac}^{+}$ colonies from each $40^{\circ} \mathrm{C}$ selection were retained as putative $\mathrm{Hfr}$ donor strains.

The Hfr donor strains (which were prototrophic and streptomycinsensitive) were grown to full density at $40^{\circ} \mathrm{C}$ in NCE lactose minimal medium and then diluted $1: 20$ into nutrient broth. The recipient strains (which were auxotrophic and streptomycin-resistant) were grown to full density in nutrient broth and then diluted $1: 5$ into the same medium. After a $2 \mathrm{~h}$ incubation at $37^{\circ} \mathrm{C}$, equal volumes $(0 \cdot 1 \mathrm{ml}$ each) of donor and recipient cells were spread onto streptomycin-containing $\mathrm{E}$ glucose minimal medium plates. Recombinants (which were prototrophic and streptomycin-resistant) were counted following a $2 \mathrm{~d}$ incubation at $37^{\circ} \mathrm{C}$.

Lac phenotype of MudA insertion strains. The presence or absence of operon fusions in the $p d u::$ MudA insertion strains was determined by testing for $\beta$-galactosidase activity on NCE succinate ( $22 \mathrm{mM}$ ) minimal medium plates that contained $\mathrm{X}-\mathrm{Gal}$ as an indicator. $\mathrm{X}-\mathrm{Gal}$ is 
hydrolysed by $\beta$-galactosidase to form a nondiffusable blue pigment. Thus, expression of the MudA-encoded lac $Z$ gene results in the formation of blue-coloured colonies (Silhavy \& Beckwith, 1985). The concentration of X-Gal in the culture medium was $25 \mathrm{mg} \mathrm{l}^{-1}$ (X-Gal was dissolved in $1 \mathrm{ml} \mathrm{N}, N$-dimethylformamide before addition to the medium). One set of plates contained propanediol ( $26 \mathrm{~mm}$ ) to induce the $p d u$ genes, and a second set of plates lacked propanediol. Strains that formed colourless colonies on both sets of plates were assigned a $\mathrm{Lac}^{-}$phenotype; strains that formed blue colonies on propanediolsupplemented plates and colourless colonies on unsupplemented plates were assigned a $\mathrm{Lac}^{+}$phenotype.

$\beta$-Galactosidase assays. $\beta$-Galactosidase enzyme activity was assayed by using the procedure of Miller (1972), except that the cell density was measured as the optical density at $650 \mathrm{~nm}$ rather than $600 \mathrm{~nm}$. The cells were permeabilized by treatment with chloroform/SDS.

Formation of duplications and deletions by recombination between MudA prophages. This method to determine the direction of gene transcription was performed as described by Hughes \& Roth (1985). P22 lysates were grown on S. typhimurium strains TT7691 and TT7692 (his D : : MudA insertions in opposite chromosomal orientations) and on 10 different strains that carried $p d u::$ MudA insertions (in unknown chromosomal orientations). Equal concentrations of phage (p.f.u. $\mathrm{ml}^{-1}$ ) from individual his and $p d u$ mutant lysates were mixed. A recipient strain (TR6583) was transduced and colonies were selected on ampicillin-containing complex medium. Each transductant colony displayed one of four possible phenotypes: $\mathrm{His}^{+} \mathrm{Pdu}^{-}(p d u:: \mathrm{MudA}$ insertion inherited); $\mathrm{His}^{-} \mathrm{Pdu}^{+}$(his $D::$ MudA insertion inherited); $\mathrm{His}^{+} \mathrm{Pdu}^{+}$(duplication of genetic material between hisD and $p d u$ generated by recombination between his $D::$ MudA and $p d u::$ MudA prophages); or His ${ }^{-} \mathrm{Pdu}^{-}$(deletion of genetic material between his $D$ and $p d u$ generated by recombination between hisD::MudA and $p d u::$ MudA prophages). One-hundred colonies were isolated from each transductional cross and their phenotypes were determined by replica plating to the appropriately supplemented minimal medium.

\section{Results}

\section{Cobalamin-dependent utilization of propanediol}

by S. typhimurium

S. typhimurium utilizes 1,2-propanediol as a sole source of carbon and energy during aerobic growth, but only when a nutritional supplement of cobalamin is also added to the culture medium. This conclusion was drawn from the growth curves of $S$. typhimurium LT2 that are shown in Fig. 1. Cells were inoculated into flasks that contained NCE propanediol minimal medium with and without the addition of cobalamin. The cultures were then incubated at $30^{\circ} \mathrm{C}$ with aeration (see Methods). After an initial slight increase in cell density (approximately one doubling), the culture that lacked cobalamin showed no further growth. By contrast, the culture that was supplied with cobalamin continued to grow steadily. Based on the best-fitting regression line through the data points, the growth rate constant $(\mu)$ for the latter culture was $0.0265 \mathrm{~h}^{-1}$, which is equivalent to a doubling time of $26 \cdot 2 \mathrm{~h}$. Thus, even when $S$. typhimurium was provided with an adequate supply of cobalamin, aerobic growth

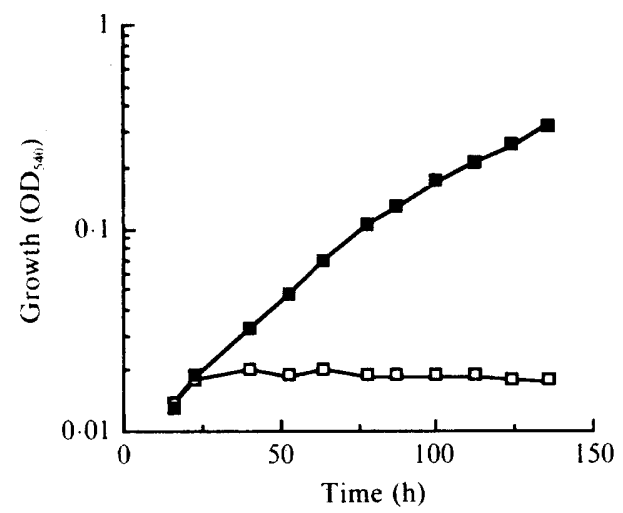

Fig. 1. Growth of $S$. typhimurium LT2 on 1,2-propanediol as a sole source of carbon and energy. Cultures were grown at $30^{\circ} \mathrm{C}$ in NCE propanediol minimal medium, with $(\boldsymbol{\square})$ and without $(\square)$ cobalamin added as a nutritional supplement (see Methods).

on propanediol was slow. $S$. typhimurium did not grow anaerobically on propanediol as a sole carbon source (data not shown), which is in agreement with previously published results (Obradors et al., 1988).

\section{Isolation of propanediol-negative MudA insertion mutants}

The defective bacteriophage MudA was introduced into $S$. typhimurium LT2 and ampicillin-resistant transductant colonies were selected as described in Methods. These colonies were screened for simultaneous loss of the ability to utilize propanediol as a sole source of carbon. Thirty-one independent mutants were isolated that possessed this phenotype. The genes that had been disrupted by the insertion mutations in these strains were designated $p d u$, for defects in propanediol utilization. Each of these mutants was tested to determine if the MudA insertion created an operon fusion $\left(\mathrm{Lac}^{+}\right.$phenotype, as detected by the formation of a blue colour on propanediol-containing X-Gal indicator plates). In 17 of the strains, the MudA element inserted into the chromosome in the correct orientation to form operon fusions $\left(\mathrm{Lac}^{+}\right)$; in the remaining 14 strains, the MudA element appeared to have inserted into the chromosome in the wrong orientation to form such fusions $\left(\mathrm{Lac}^{-}\right)$. For the strain designation, genotype and phenotypic classification $\left(\mathrm{Lac}^{+}\right.$or $\mathrm{Lac}^{-}$) of all of these MudA insertion mutants, see Table 3 .

Aerobically, the cobalamin-dependent utilization of 1,2-propanediol entails its conversion into propionate. Propionate is then metabolized in several steps to pyruvate (Fernández-Briera \& Garrido-Pertierra, 1988; Wegener et al., 1967). All of the Pdu- strains grew well on propionate as a sole source of carbon (data not shown). 
Table 2. Propanediol dehydratase enzyme activities in extracts of $S$. typhimurium

Each value shown in the table represents a single determination.

\begin{tabular}{|c|c|c|}
\hline \multirow[b]{2}{*}{$\begin{array}{l}\text { Strain and } \\
\text { genotype }\end{array}$} & \multicolumn{2}{|c|}{$\begin{array}{l}\text { Specific activity } \\
\left.\text { [nmol propionaldehyde formed } \text { min }^{-1}(\text { mg protein })^{-1}\right]\end{array}$} \\
\hline & $\begin{array}{l}\text { Cells grown without } 1,2 \text {-propanediol } \\
\text { and cyanocobalamin }\end{array}$ & $\begin{array}{l}\text { Cells grown with } 1,2 \text {-propanediol } \\
\text { and cyanocobalamin }\end{array}$ \\
\hline LT2 $\left(p d u^{+}\right)$ & $3 \cdot 1$ & 1900 \\
\hline RT811 (pdu-1:: MudA) & $6 \cdot 8$ & $3 \cdot 5$ \\
\hline RT813 (pdu-3:: MudA) & $7 \cdot 1$ & 1700 \\
\hline RT818 ( $p d u-8::$ MudA $)$ & $2 \cdot 5$ & 1900 \\
\hline RT822 (pdu-12::MudA) & $4 \cdot 6$ & $4 \cdot 2$ \\
\hline
\end{tabular}

However, 12 additional MudA insertion mutants were isolated from the selection that were unable to utilize either propanediol or propionate as sole sources of carbon for growth. These strains (not listed in Table 3) appear to be blocked in one or more steps of propionate metabolism.

\section{Propanediol dehydratase enzyme activity}

S. typhimurium LT2 and four $p d u::$ MudA insertion mutants (RT811, RT813, RT818 and RT822) were assayed to determine the levels of propanediol dehydratase enzyme activity. Aerobic cultures of each strain were grown in NCE succinate minimal medium with and without supplements of propanediol and cobalamin. Crude extracts were prepared and then assayed to determine the rate of propionaldehyde formation from propanediol (see Methods). The results of these enzyme assays are presented in Table 2 . All of the extracts had extremely low activities [0.34 to $2.6 \mathrm{nmol}$ propionaldehyde formed $\min ^{-1}$ (mg protein) $\left.{ }^{-1}\right]$ when the substrate was not added to the assay tubes (data not shown). These numbers set an upper limit for the amounts of endogenous propanediol that were initially present in the crude extracts. In the tubes that contained the complete assay mixture, the extracts from cells that had been grown in medium without supplements of propanediol and cobalamin had only slightly higher activities $[2.5$ to $7.1 \mathrm{nmol}$ propionaldehyde formed $\mathrm{min}^{-1}$ (mg protein $)^{-1}$. These numbers indicate that little active enzyme is synthesized when propanediol and cobalamin are both absent. The extracts from cells that had been grown in medium with supplements of propanediol and cobalamin produced mixed results. The wild-type strain (LT2) and two of the mutants (RT813 and RT818) had large amounts of propanediol dehydratase activity [1700 to $1900 \mathrm{nmol}$ propionaldehyde formed $\mathrm{min}^{-1}$ (mg protein $)^{-1}$ ]. The other two mutants (RT811 and RT822) had only low levels of activity [ 3.5 and $4.2 \mathrm{nmol}$ propionaldehyde formed $\mathrm{min}^{-1}$ (mg protein) $\left.{ }^{-1}\right]$. These numbers demonstrate that two of the insertions ( $p d u-1::$ MudA and $p d u-12:: \mathrm{MudA}$ ) block the synthesis of propanediol dehydratase directly, but that the other two insertions ( $p d u-3::$ MudA and $p d u-8::$ MudA) do not. The latter mutations probably exert their phenotypic effects by blocking the synthesis of enzymes in the pathway other than propanediol dehydratase.

\section{Genetic mapping of the pdu mutations by conjugation}

Conjugational mapping experiments were done to locate the $p d u$ genes on the $S$. typhimurium chromosome. Hfr donor strains were constructed by selecting for homologous recombination between the lac genes of an F'lac plasmid and a MudA prophage (see Methods). Under these conditions, integration of the $F^{\prime}$ (and hence the origin of chromosomal transfer) occurs at the site of the MudA insertion and the direction of chromosomal transfer is governed by the orientation of the MudA insertion (Maloy \& Roth, 1983). Thus, two different $p d u:$ :MudA insertions with opposite Lac phenotypes were used to construct the $\mathrm{Hfr}$ strains so that the position of the $p d u$ locus could be determined by chromosomal transfer in both directions. These insertions were $p d u-3$ $::$ MudA (RT813, Lac ${ }^{-}$phenotype) and pdu-8::MudA (RT818, $\mathrm{Lac}^{+}$phenotype). The Hfr donors were then mated with a set of auxotrophic recipients as described previously (Chumley et al., 1979; Davis et al., 1980). In both sets of matings, a clear (greater than 10-fold) discontinuity in the numbers of prototrophic recombinants occurred between aroD and his (data not shown). These data place the $p d u$ locus between 36 and 42 map units (Sanderson \& Roth, 1988).

\section{$P d u^{-}$phenotype of mutants that carry his-cob deletions}

The genes for cobalamin biosynthesis (cob) are located at 41 map units on the $S$. typhimurium chromosome (Jeter $e t$ al., 1984). Since propanediol utilization is dependent 
upon cobalamin, it seemed reasonable to speculate that the $p d u$ genes were located near the cob locus. To test this hypothesis, five independently isolated mutant strains (RT761-RT765) that carried chromosomal deletions extending from the his operon into the $c o b$ operons were tested for their ability to metabolize propanediol. Cobalamin and histidine were present in the culture medium as nutritional supplements. None of the deletion strains was able to utilize propanediol as a sole source of carbon for growth (data not shown). By contrast, all of the parental strains (TR6583, RT766, RT767 and RT785) grew well on this same medium. These results provide strong phenotypic evidence that the $p d u$ genes are located between the his and $c o b$ genes.

All the deletion and control strains grew well on propionate as a sole source of carbon. These results demonstrate that only genes that are required for the conversion of propanediol to propionate lie between the his and $c o b$ operons. Genes that are required for the degradation of propionate are located elsewhere on the $S$. typhimurium chromosome.

All the deletion and control strains grew well on ethanolamine as a sole source of carbon. Thus, the activity of ethanolamine ammonia-lyase was not impaired. The strains also carried the metE205 mutation, which makes the synthesis of methionine completely dependent upon the activity of the cobalamin-requiring metH enzyme (Jeter et al., 1984). These results demonstrate that the deletion of genetic material between the his and $c o b$ genes causes a specific loss of the ability to utilize propanediol, but does not create any obvious defects in other aspects of known cobalamin metabolism (e.g. cobalamin transport, ethanolamine utilization and cobalamin-dependent homocysteine methylation).

\section{Cotransductional linkage of pdu to cob}

All the insertion mutants that had a $\mathrm{Pdu}^{-}$phenotype were tested for cotransduction with the branch I cob operon. Each mutant was transduced with a bacteriophage P22 lysate that had been grown on a donor strain carrying a his-proximal Tn10 insertion in the branch I $c o b$ genes (TT10441; cob-13::Tn 10). Tetracycline-resistant transductant colonies were then tested for loss of the $p d u:$ :MudA insertion (ampicillin-sensitive phenotype). A donor control cross was done with a recipient that carried a MudA insertion in the his operon (TT7691; hisD9952::MudA). The his genes are too distant to be cotransduced with the branch I cob genes (Jeter et al., 1984). In the same manner, recipient control crosses were done with a P22 lysate that had been grown on a donor strain carrying a distant Tn10 insertion (TT6195; pncA148:: $\operatorname{Tn} 10$ ). The results of these transductions are presented in Table 3. Out of 31 mutants with a $\mathrm{Pdu}^{-}$
Table 3. MudA insertions in the pdu genes and their cotransductional linkages to a branch I cob: :Tn10 allele

Recipients were the MudA insertion strains and donor bacteriophage was grown on strain TT10441 (cob-13::Tn10).

\begin{tabular}{|c|c|}
\hline $\begin{array}{l}\text { Strain designation, genotype } \\
\text { and Lac phenotype }\end{array}$ & $\begin{array}{l}\text { No. of } \operatorname{Tet}^{r} \mathrm{Amp}^{\mathrm{s}} \text { transductants } \\
\text { (per } 100 \text { scored) }\end{array}$ \\
\hline RT811 (pdu-l::MudA, Lac $\left.{ }^{-}\right)$ & 25 \\
\hline RT812 (pdu-2::MudA, $\left.\mathrm{Lac}^{-}\right)$ & 5 \\
\hline RT813 (pdu-3::MudA, Lac $\left.{ }^{-}\right)$ & 5 \\
\hline RT814 (pdu-4::MudA, $\left.\mathrm{Lac}^{-}\right)$ & 5 \\
\hline RT815 (pdu-5::MudA, $\left.\mathrm{Lac}^{+}\right)$ & 13 \\
\hline RT816 (pdu-6:: MudA, Lac $\left.^{-}\right)$ & 13 \\
\hline RT817 (pdu-7:: MudA, $\left.\mathrm{Lac}^{-}\right)$ & 22 \\
\hline RT818 (pdu-8:: MudA, $\left.\mathrm{Lac}^{+}\right)$ & 7 \\
\hline RT819 (pdu-9:: MudA, $\left.\mathrm{Lac}^{+}\right)$ & 18 \\
\hline RT820 (pdu-10::MudA, $\left.\mathrm{Lac}^{-}\right)$ & 14 \\
\hline RT821 (pdu-11::MudA, $\left.\mathrm{Lac}^{+}\right)$ & 11 \\
\hline RT822 (pdu-12::MudA, $\left.\mathrm{Lac}^{+}\right)$ & 24 \\
\hline RT823 (pdu-13::MudA, $\left.\mathrm{Lac}^{+}\right)$ & 6 \\
\hline RT824 (pdu-14::MudA, Lac $\left.^{-}\right)$ & 11 \\
\hline RT825 (pdu-15::MudA, $\left.\mathrm{Lac}^{+}\right)$ & 10 \\
\hline RT826 (pdu-16::MudA, $\left.\mathrm{Lac}^{+}\right)$ & 8 \\
\hline RT827 ( $p d u-17::$ MudA, $\left.\mathrm{Lac}^{+}\right)$ & 11 \\
\hline RT828 ( $p d u-18::$ MudA, $\left.\mathrm{Lac}^{+}\right)$ & 15 \\
\hline RT829 (pdu-19::MudA, $\left.\mathrm{Lac}^{-}\right)$ & 35 \\
\hline RT830 (pdu-20:: MudA, $\left.\mathrm{Lac}^{+}\right)$ & 16 \\
\hline RT831 (pdu-21::MudA, Lac $\left.{ }^{+}\right)$ & 8 \\
\hline RT832 (pdu-22::MudA, $\left.\mathrm{Lac}^{-}\right)$ & 2 \\
\hline RT833 (pdu-23:: MudA, Lac $\left.{ }^{+}\right)$ & 6 \\
\hline RT834 (pdu-24::MudA, $\left.\mathrm{Lac}^{+}\right)$ & 17 \\
\hline RT835 (pdu-25:: MudA, $\left.\mathrm{Lac}^{+}\right)$ & 9 \\
\hline RT836 (pdu-26:: MudA, $\left.\mathrm{Lac}^{-}\right)$ & 7 \\
\hline RT837 (pdu-27::MudA, $\left.\mathrm{Lac}^{+}\right)$ & 7 \\
\hline RT838 ( $p d u-28::$ MudA, Lac $\left.^{+}\right)$ & 20 \\
\hline RT839 (pdu-29:: MudA, Lac $\left.{ }^{-}\right)$ & 17 \\
\hline RT848 (pdu-32::MudA, $\left.\mathrm{Lac}^{-}\right)$ & 4 \\
\hline RT847 (btu-151::MudA, Lac $^{-}$) & 0 \\
\hline
\end{tabular}

phenotype, 30 (RT811-RT839 and RT848) displayed linkage between the site of the MudA insertion and the $c o b-13$ allele. The range in the cotransduction frequencies was from 2 to $35 \%$ and the mean was $12 \%$. As expected, none of the insertions showed any cotransduction with each other in the control crosses (data not shown).

The cotransduction frequencies between the $p d u$ and $c o b$ alleles were converted into physical distance along the chromosome as follows. Bacteriophage P22 DNA molecules that are packaged into phage heads by the P22 headful nuclease have a mean length of $43.4 \mathrm{kbp}$ (Casjens \& Hayden, 1988). Donor bacterial DNA molecules that are packaged into P22 transducing particles were assumed to have the same length. Thus, the DNA that was introduced into the recipient cells in these transductions consisted of the $\mathrm{Tn} 10$ transposon $(9.3 \mathrm{kbp})$ and flanking chromosomal sequences $(34.1 \mathrm{kbp})$. Using the latter number in the formula of $\mathrm{Wu}$ (1966), it was calculated that cotransduction frequencies 
of 2 and $35 \%$ corresponded to distances of 25 and $10 \mathrm{kbp}$ of DNA, respectively. The mean cotransduction frequency $(12 \%)$ corresponded to a mean physical distance of $17 \mathrm{kbp}$ of DNA.

The one remaining propanediol-negative strain (RT847) that did not display any cotransduction between the MudA insertion and the cob-13 allele also did not grow on ethanolamine as a sole carbon source. This result suggested that the mutation might block the transport of cobalamin. The MudA insertion was tested for cotransduction with a $\operatorname{Tn} 10$ insertion (TT13787; btu-6::Tn10) that confers a defect in cobalamin uptake and may occur in the $b t u C$ locus (D. M. Roof, personal communication). The two insertions were found to be $98 \%$ cotransducible (data not shown). Thus, the mutation in RT847 was assigned as a defect in cobalamin transport (btu-151 ::MudA).

\section{Identification of propanediol-negative Tn10 insertion mutants}

Two strains (TT10927 and TT11073) that were isolated previously carry independent $\operatorname{Tn} 10$ insertions in the $S$. typhimurium chromosome that are cotransducible with (but do not disrupt) the branch I cob operon (Jeter \& Roth, 1987). The $\operatorname{Tn} 10$ insertions were originally assigned the allele designations zeb-1845::Tn 10 and $z e b-1847:: \operatorname{Tn} 10$, respectively. In this study, these two strains were tested for propanediol utilization and were found to have a $\mathrm{Pdu}^{-}$phenotype. Thus, the insertions were reclassified as $p d u-30:: \operatorname{Tn} 10$ and $p d u-31:: \operatorname{Tn} 10$ (Table 1).

\section{Direction of transcription of the pdu genes}

The method of Hughes \& Roth (1985) was used to determine the direction of transcription of the $p d u$ genes. In this procedure, bacteriophage P22 lysates are grown on different MudA insertion strains, the lysates are mixed in pairs, and recipient cells are infected separately with each mixed lysate. Individual transductants may inherit either one of the parental MudA elements irrespective of its orientation in the chromosome. When the parental MudAs are in the same relative orientation, homologous recombination can also occur between them to produce hybrid MudA elements. Inheritance of such a hybrid generates a duplication or deletion of the genetic material between the original MudA insertion sites. The phenotypes that are conferred by these chromosomal rearrangements are distinguishable from the phenotypes of the parental strains. Thus, if the chromosomal orientation of one of the parental MudA insertions is known, the orientation of the second MudA insertion can be inferred (Hughes \& Roth, 1985).

P22 lysates were grown on two different his $D:$ : MudA insertion strains and 10 different $p d u::$ MudA insertion strains, and 20 mixed lysates were prepared. Recipient cells (TR6583) were then infected with each of the mixed lysates, ampicillin-resistant transductants were selected, and their phenotypes were determined. The results of these genetic crosses are given in Table 4. To summarize the data, the $\mathrm{Lac}^{+}$his $D::$ MudA insertion formed duplications and deletions when combined with all of the $\mathrm{Lac}^{+} p d u::$ MudA insertions, but not when combined with any of the $\mathrm{Lac}^{-} p d u$ : : MudA insertions. Conversely, the $\mathrm{Lac}^{-}$his $D:: \mathrm{MudA}$ insertion formed duplications and deletions when combined with all of the $\mathrm{Lac}^{-}$ $p d u:$ : MudA insertions, but not when combined with any of the $\mathrm{Lac}^{+} p d u::$ MudA insertions. Thus, his $D::$ MudA and $p d u::$ MudA insertions that shared the same Lac phenotypes were in the same chromosomal orientations, and his $D::$ MudA and $p d u::$ MudA insertions that had different Lac phenotypes were in opposite chromosomal orientations. The his operon is known to be transcribed in the clockwise direction relative to the $S$. typhimurium genetic map (Sanderson \& Roth, 1988). Thus, all of the $p d u$ genes that were tested are also transcribed in the clockwise direction.

\section{Regulation of the pdu genes}

Two $p d u$ : : lac operon fusion strains (RT818 and RT822) were grown aerobically and assayed for $\beta$-galactosidase enzyme activity. Aerobic cultures were grown in minimal medium with succinate (a poor carbon source), and the ability of exogenously supplied propanediol and cyanocobalamin to induce the fusions was tested. The results of these assays are given in Table 5 . Virtually no $\beta$ galactosidase activity was observed in the fusion strains when both supplements were absent or when cobalamin alone was present in the culture medium. By contrast, $\beta$-galactosidase was strongly induced by the presence of propanediol alone. In the presence of propanediol, cobalamin appeared to enhance the induction in one of the fusion strains (RT822), but not in the other fusion strain (RT818).

\section{Discussion}

In this paper, I have presented evidence that the enteric bacterium $S$. typhimurium is able to utilize 1,2-propanediol as a sole source of carbon and energy during aerobic growth. However, the aerobic metabolism of propanediol is dependent upon the provision of cobalamin as a nutritional supplement. This requirement is due to the 
Table 4. Chromosomal orientation of pdu::MudA insertions

A total of 100 colonies were scored in each transductional cross. In control crosses with unmixed lysates, the inheritance of a parental MudA insertion always conferred the expected parental phenotype (data not shown).

\begin{tabular}{|c|c|c|c|c|c|}
\hline \multirow[b]{2}{*}{$\begin{array}{l}\text { MudA insertion that is } \\
\text { carried by donor strains }\end{array}$} & \multicolumn{4}{|c|}{ No. of transductant colonies with phenotype } & \multirow{2}{*}{$\begin{array}{l}\text { Inferred relative } \\
\text { orientation of } \\
\text { MudA elements }\end{array}$} \\
\hline & $\begin{array}{c}\text { Parental } \\
\left(\mathrm{Pdu}^{-} \mathrm{His}^{+}\right)\end{array}$ & $\begin{array}{c}\text { Parental } \\
\left(\mathrm{Pdu}^{+} \mathrm{His}^{-}\right)\end{array}$ & $\begin{array}{l}\text { Duplication } \\
\left(\mathrm{Pdu}^{+} \mathrm{His}^{+}\right)\end{array}$ & $\begin{array}{c}\text { Deletion } \\
\left(\mathrm{Pdu}^{-} \mathrm{His}^{-}\right)\end{array}$ & \\
\hline \multicolumn{6}{|l|}{$\mathrm{Lac}^{-} p d u+\mathrm{Lac}^{-} h i s$} \\
\hline$p d u-2+h i s D 9952$ & 26 & 38 & 33 & 3 & \multirow{5}{*}{ Same } \\
\hline$p d u-7+$ his $D 9952$ & 3 & 38 & 43 & 16 & \\
\hline pdu-14 + hisD 9952 & 14 & 43 & 30 & 13 & \\
\hline pdu-19+hisD 9952 & 33 & 21 & 46 & 0 & \\
\hline$p d u-29+$ hisD 9952 & 26 & 7 & 56 & 11 & \\
\hline \multicolumn{5}{|l|}{$\mathrm{Lac}^{-} p d u+\mathrm{Lac}^{+} h i s$} & \multirow{6}{*}{ Opposite } \\
\hline$p d u-2+h i s D 9953$ & 62 & 38 & 0 & 0 & \\
\hline pdu-7 + hisD9953 & 68 & 32 & 0 & 0 & \\
\hline pdu-14 + hisD9953 & 62 & 38 & 0 & 0 & \\
\hline$p d u-19+$ his $D 9953$ & 56 & 44 & 0 & 0 & \\
\hline$p d u-29+$ hisD 9953 & 76 & 24 & 0 & 0 & \\
\hline \multicolumn{5}{|l|}{$\mathrm{Lac}^{+} p d u+\mathrm{Lac}^{-} h i s$} & \multirow{6}{*}{ Opposite } \\
\hline$p d u-9+h i s D 9952$ & 28 & 72 & 0 & 0 & \\
\hline pdu-11 + hisD9952 & 65 & 35 & 0 & 0 & \\
\hline$p d u-13+$ hisD 9952 & 73 & 27 & 0 & 0 & \\
\hline pdu-18+hisD 9952 & 58 & 42 & 0 & 0 & \\
\hline$p d u-28+h i s D 9952$ & 79 & 21 & 0 & 0 & \\
\hline \multicolumn{5}{|l|}{$\mathrm{Lac}^{+} p d u+\mathrm{Lac}^{+} h i s$} & \multirow{6}{*}{ Same } \\
\hline pdu-9 + hisD 9953 & 19 & 8 & 53 & 20 & \\
\hline pdu-1I+ hisD 9953 & 35 & 5 & 51 & 9 & \\
\hline pdu-13+ hisD 9953 & 28 & 3 & 62 & 7 & \\
\hline pdu-18+hisD 9953 & 44 & 9 & 40 & 7 & \\
\hline pdu-28+hisD 9953 & 51 & 2 & 41 & 6 & \\
\hline
\end{tabular}

* The phenotypes of individual $p d u$ and his alleles are given as $\mathrm{Lac}^{+}$(if $p d u:: l a c$ or his : :lac operon fusions were formed) or Lac (if operon fusions were not formed). The strain numbers that correspond to the alleles are given in Tables 1 and 3.

Table 5. Regulation of $\beta$-galactosidase activity in pdu: :lac operon fusion strains.

Each value shown in the Table represents the mean of three determinations. Strain LT2 was used as a negative control and had 0.6 units of specific activity. All cultures were grown in NCE succinate minimal medium with the addition of cyanocobalamin $(15 \mathrm{nM})$ or 1,2-propanediol $(26 \mathrm{~mm})$ or both as indicated.

\begin{tabular}{lcc}
\hline \hline & \multicolumn{2}{c}{$\begin{array}{c}\text { Specific activity } \\
\text { [nmol } o \text {-nitrophenol formed } \text { min }^{-1} \\
\left.\left(\text { OD }_{650} \text { unit }\right)^{-1}\right]\end{array}$} \\
\cline { 2 - 3 } $\begin{array}{c}\text { Supplement(s) added } \\
\text { to culture medium }\end{array}$ & $\begin{array}{c}\text { RT818 } \\
(p d u-8:: \text { MudA) }\end{array}$ & $\begin{array}{c}\text { RT822 } \\
(p d u-12:: \text { MudA) })\end{array}$ \\
\hline None & $2 \cdot 2$ & 1.5 \\
Cobalamin & $1 \cdot 5$ & 1.8 \\
Propanediol & 1800 & $2600^{*}$ \\
Cobalamin + propanediol & 1900 & $3800^{*}$ \\
\hline \hline
\end{tabular}

* In an unpaired $t$-test, the two sets of data were different $(P<0.001)$.

fact that $S$. typhimurium synthesizes cobalamin de novo only when the cells are grown under anaerobic conditions (Jeter et al., 1984). In the presence of oxygen, propanediol is first dehydrated to form propionaldehyde, a reaction which is catalysed by the cobalamin-dependent enzyme propanediol dehydratase. Propionaldehyde is then converted by one or more additional enzymes into propionate (or propionyl coenzyme A). Lastly, propionate is metabolized by a poorly characterized pathway that is thought to proceed via the intermediates acrylyl coenzyme $\mathrm{A}$ and lactyl coenzyme $\mathrm{A}$ to pyruvate (Fernández-Briera \& Garrido-Pertierra, 1988; Wegener et al., 1967).

The discovery that $S$. typhimurium utilizes propanediol as a sole carbon source aerobically provided the opportunity to isolate mutants that are blocked in propanediol metabolism. Based upon these mutations, the genes for propanediol utilization $(p d u)$ were located between the his and branch I $c o b$ operons at 41 map units on the S. typhimurium chromosome (Table 3 ). This region is shown diagrammatically in Fig. 2. The range in cotransduction frequencies between $p d u$ and $c o b$ alleles suggested that the $p d u$ region spans roughly $15 \mathrm{kbp}$ of DNA (see Results). Toraya et al. (1979) have studied anaerobic propanediol metabolism in K. pneumoniae and have proposed that the fermentative propanediol dehydratase pathway comprises five different enzyme 


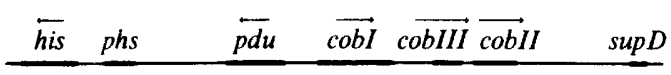

Fig. 2. Genetic map of the $p d u$ region on the $S$. typhimurium chromosome. The depicted region is drawn to approximate scale and is estimated to be about 3 map units in length. Arrows above the genes indicate the known directions of transcription. Gene designations: his, histidine biosynthesis; phs, production of hydrogen sulphide; $p d u$, propanediol utilization; cob, cobalamin biosynthesis; sup $D$, amber suppressor.

activities. Propanediol dehydratase itself has been reported to consist of at least four nonidentical subunits (McGee \& Richards, 1981; Poznanskaja et al., 1979). Thus, it is not surprising that the $p d u$ region of the $S$. typhimurium chromosome might be so large.

Some but not all of the $p d u$ mutants that were assayed had lost the ability to synthesize propanediol dehydratase holoenzyme (Table 2). The two insertions ( $p d u-1$ $::$ MudA and $p d u-12::$ MudA) that resulted in loss of

the enzyme activity also displayed high frequencies of cotransduction ( 25 and $24 \%$ ) with the branch I cob::Tn 10 insertion (Table 3). By contrast, the two insertions ( $p d u-3::$ MudA and $p d u-8::$ MudA) that did not result in loss of the enzyme activity displayed low frequencies of cotransduction ( 5 and $7 \%$ ) with the same marker. A likely explanation for these results is that the structural genes for propanediol dehydratase lie at the $c o b$-proximal end of the $p d u$ region. Additional biochemical and genetic analysis of the pdu mutants will be necessary in order to confirm this hypothesis.

Several his-cob deletion mutants were tested and found to lack the ability to grow on propanediol as a sole carbon source. However, they all grew well on propionate alone. These results demonstrate that the genes for propionate metabolism do not lie in this interval of the $S$. typhimurium chromosome. Likewise, all the deletion mutants retained the abilities to use ethanolamine as a sole carbon source and to synthesize methionine in a cobalamin-dependent fashion. Thus, these deletions confer a specific defect in propanediol utilization but do not directly impair other cobalamin-dependent metabolic activities in the cells.

Transcription of the $p d u$ genes was strongly induced by the presence of propanediol in the culture medium (Table 5). One of the tested strains (RT822) was not able to metabolize propanediol, since it completely lacked propanediol dehydratase activity (Table 2 ). Thus, propanediol itself appears to be the true inducer.

Cyanocobalamin alone had no effect on $p d u$ gene expression. In combination with propanediol, it appeared to stimulate transcription of the $p d u:: l a c$ fusion in RT822 but not the fusion in RT818 (Table 5). A possible explanation for this observation is that the $p d u$ genes encoding propanediol dehydratase itself may be organized into a transcriptional unit that responds to both cobalamin and propanediol, while the $p d u$ genes encoding other enzyme activities are organized into one or more separate transcriptional units that do not respond to cobalamin. The operon organization of these genes is currently under investigation. In any case, the $p d u$ genes appear to be regulated differently than the eut operon, for which the induction of transcription requires the simultaneous presence of both ethanolamine and cobalamin (Roof \& Roth, 1988).

Transcription of the $c o b$ genes is repressed in response to molecular oxygen (Escalante-Semerena \& Roth, 1987). It is reasonable to assume that this gives $S$. typhimurium some selective advantage for continued survival in its natural habitat, the mammalian intestinal tract. However, the precise nature of this advantage has remained elusive. The location of the genes for propanediol utilization near the genes for cobalamin biosynthesis suggests that these two sets of genes may share a close evolutionary relationship. Thus, future genetic and biochemical studies of propanediol metabolism by $S$. typhimurium may add to our understanding of this most puzzling aspect of $c o b$ gene regulation.

I thank Ronald Smith for assistance in isolating the $p d u:$ :MudA insertion strains and Karin Otto for critically reading the manuscript. This research was supported by a grant from the College of Arts and Sciences at Texas Tech University.

\section{References}

Abeles, R. H. \& LEE, H. A., JR (1961). An intramolecular oxidationreduction requiring a cobamide coenzyme. Journal of Biological Chemistry 236, 2347-2350.

Anderson, R. P. \& Roth, J. R. (1978). Tandem chromosomal duplications in Salmonella typhimurium: fusion of histidine genes to novel promoters. Journal of Molecular Biology 119, 147-166.

BJörK, G. R. (1987). Modification of stable RNA. In Escherichia coli and Salmonella typhimurium: Cellular and Molecular Biology, pp. 719731. Edited by F. C. Neidhardt, J. L. Ingraham, K. B. Low, B. Magasanik, M. Schaechter \& H. E. Umbarger. Washington, DC: American Society for Microbiology.

Björk, G. R., Ericson, J. U., Gustafsson, C. E. D., Hagervall, T. G., Jönsson, Y. H. \& WikströM, P. M. (1987). Transfer RNA modification. Annual Review of Biochemistry 56, 263-287.

BOCHNER, B. R. (1984). Curing bacterial cells of lysogenic viruses by using UCB indicator plates. BioTechniques 2, 234-240.

Casadaban, M. J. \& Cohen, S. N. (1979). Lactose genes fused to exogenous promoters in one step using a Mu-lac bacteriophage: in vivo probe for transcriptional control sequences. Proceedings of the National Academy of Sciences of the United States of America 76, 4530-4533.

CASJENS, S. \& HAYDEN, M. (1988). Analysis in vivo of the bacteriophage P22 headful nuclease. Journal of Molecular Biology 199, 467-474.

Castilho, B. A., Olfson, P. \& Casadaban, M. J. (1984). Plasmid insertion mutagenesis and lac gene fusion with mini-Mu bacteriophage transposons. Journal of Bacteriology 158, 488-495.

Cauthen, S. E., Foster, M. A. \& Woods, D. D. (1966). Methionine synthesis by extracts of Salmonella typhimurium. Biochemical Journal $98,630-635$. 
Chang, G. W. \& Chang, J. T. (1975). Evidence for the $B_{12}$-dependent enzyme ethanolamine deaminase in Salmonella. Nature, London 254, $150-151$.

CHILDS, J. D. \& SMITH, D. A. (1969). New methionine structural gene in Salmonella typhimurium. Journal of Bacteriology 100, 377-382.

Chumley, F. G., MENZel, R. \& Roth, J. R. (1979). Hfr formation directed by $\mathrm{Tn} 10$. Genetics $91,639-655$.

DAvis, R. W., Botstein, D. \& RoTH, J. R. (1980). Advanced Bacterial Genetics. Cold Spring Harbor, NY: Cold Spring Harbor Laboratory.

Escalante-Semerena, J. C. \& Roth, J. R. (1987). Regulation of cobalamin biosynthetic operons in Salmonella typhimurium. Journal of Bacteriology 169, 2251-2258.

Fernández-Briera, A. \& Garrido-Pertierra, A. (1988). A degradation pathway of propionate in Salmonella typhimurium LT-2. Biochimie 70, 757-768.

FoRAGE, R. G. \& FosTER, M. A. (1982). Glycerol fermentation in Klebsiella pneumoniae: functions of the coenzyme $\mathrm{B}_{12}$-dependent glycerol and diol dehydratases. Journal of Bacteriology 149, 413-419.

Frey, B., McCloskey, J., Kersten, W. \& Kersten, H. (1988). New function of vitamin $B_{12}$ : cobamide-dependent reduction of epoxyqueuosine to queuosine in tRNAs of Escherichia coli and Salmonella typhimurium. Journal of Bacteriology 170, 2078-2082.

Hughes, K. T., CoOkson, B. T., Ladika, D., Olivera, B. M. \& Roth, J. R. (1983). 6-Aminonicotinamide-resistant mutants of Salmonella typhimurium. Journal of Bacteriology 154, 1126-1136.

Hughes, K. T. \& RoTH, J. R. (1984). Conditionally transpositiondefective derivative of Mudl(Amp Lac). Journal of Bacteriology 159, 130-137.

Hughes, K. T. \& RoTH, J. R. (1985). Directed formation of deletions and duplications using Mud(Ap, lac). Genetics 109, 263-282.

Hughes, K. T. \& Roth, J. R. (1988). Transitory cis complementation: a method for providing transposition functions to defective transposons. Genetics 119, 9-12.

JACOB, F., BRENNER, S. \& CUZIN, F. (1963). On the regulation of DNA replication in bacteria. Cold Spring Harbor Symposia on Quantitative Biology 28, 329-348.

JeTER, R. M. \& RoTH, J. R. (1987). Cobalamin (vitamin $B_{12}$ ) biosynthetic genes of Salmonella typhimurium. Journal of Bacteriology 169, 3189-3198.

Jeter, R. M., Olivera, B. M. \& Roth, J. R. (1984). Salmonella typhimurium synthesizes cobalamin (vitamin $\mathrm{B}_{12}$ ) de novo under anaerobic growth conditions. Journal of Bacteriology 159, 206-213.

Jeter, R., Escalante-Semerena, J. C., Roof, D., Olivera, B. \& RoTH, J. (1987). Synthesis and use of vitamin B ${ }_{12}$. In Escherichia coli and Salmonella typhimurium: Cellular and Molecular Biology, pp. 551556. Edited by F. C. Neidhardt, J. L. Ingraham, K. B. Low, B. Magasanik, M. Schaechter \& H. E. Umbarger. Washington, DC: American Society for Microbiology.

LeE, H. A., JR \& ABeLES, R. H. (1963). Purification and properties of dioldehydrase, an enzyme requiring a cobamide coenzyme. Journal of Biological Chemistry 238, 2367-2373.

MCGeE, D. E. \& Richards, J. H. (1981). Purification and subunit characterization of propanediol dehydratase, a membrane-associated enzyme. Biochemistry 20, 4293-4298.

MALOY, S. R. \& ROTH, J. R. (1983). Regulation of proline utilization in Salmonella typhimurium: characterization of put::Mud(Ap, lac $)$ operon fusions. Journal of Bacteriology 154, 561-568.

MilleR, J. H. (1972). Experiments in Molecular Genetics. Cold Spring Harbor, NY: Cold Spring Harbor Laboratory.
Obradors, N., Badía, J., Baldomà, L. \& Agullar, J. (1988). Anaerobic metabolism of the L-rhamnose fermentation product 1,2 propanediol in Salmonella typhimurium. Journal of Bacteriology 170, 2159-2162.

Paz, M. A., Blumenfeld, O. O., RoJkind, M., Henson, E., Furfine, C. \& GalloP, P. M. (1965). Determination of carbonyl compounds with $N$-methylbenzothiazolone hydrazone. Archives of Biochemistry and Biophysics 109, 548-559.

Poznanskaja, A. A., Tanizawa, K., Soda, K., Toraya, T. \& Fukui, S. (1979). Coenzyme $B_{12}$-dependent diol dehydrase: purification, subunit heterogeneity, and reversible association. Archives of Biochemistry and Biophysics 194, 379-386.

Roof, D. M. \& RotH, J. R. (1988). Ethanolamine utilization in Salmonella typhimurium. Journal of Bacteriology 170, 3855-3863.

SANDERSON, K. E. \& Roth, J. R. (1988). Linkage map of Salmonella typhimurium, edition VII. Microbiological Reviews 52, 485-532.

SaWicki, E., Hauser, T. R., Stanley, T. W. \& Elbert, W. (1961). The 3-methyl-2-benzothiazolone hydrazone test. Sensitive new methods for the detection, rapid estimation, and determination of aliphatic aldehydes. Analytical Chemistry 33, 93-96.

SCHMID, M. B. \& ROTH, J. R. (1983). Genetic methods for analysis and manipulation of inversion mutations in bacteria. Genetics 105, 517-537.

SCHMIEGER, H. (1971). A method for detection of phage mutants with altered transducing ability. Molecular and General Genetics 110, 378-381.

SCHMIEGER, H. (1972). Phage P22-mutants with increased or decreased transduction abilities. Molecular and General Genetics 119, 75-88.

Silhavy, T. J. \& BeCKWITH, J. R. (1985). Uses of lac fusions for the study of biological problems. Microbiological Reviews 49, 398-418.

SMITH, D. A. (1961). Some aspects of the genetics of methionineless mutants of Salmonella typhimurium. Journal of General Microbiology $24,335-353$.

Smith, H. O. \& Levine, M. (1967). A phage P22 gene controlling integration of prophage. Virology 31, 207-216.

Smith, P. K., Krohn, R. I., Hermanson, G. T., Mallia, A. K., Gartner, F. H., Provenzano, M. D., Fujimoto, E. K., Goeke, N. M., Olson, B. J. \& KLENK, D. C. (1985). Measurement of protein using bicinchoninic acid. Analytical Biochemistry 150, 76-85.

SoDA, K. (1967). A spectrophotometric microdetermination of keto acids with 3-methyl-2-benzothiazolone hydrazone. Agricultural and Biological Chemistry 31, 1054-1060.

Toraya, T., Ushio, K., Fukui, S. \& Hogenkamp, H. P. C. (1977). Studies on the mechanism of the adenosylcobalamin-dependent diol dehydrase reaction by the use of analogs of the coenzyme. Journal of Biological Chemistry 252, 963-970.

Toraya, T., Honda, S. \& Fukui, S. (1979). Fermentation of 1,2propanediol and 1,2-ethanediol by some genera of Enterobacteriaceae, involving coenzyme $\mathrm{B}_{12}$-dependent diol dehydratase. Journal of Bacteriology 139, 39-47.

VOGEL, H. J. \& BONNER, D. M. (1956). Acetylornithinase of Escherichia coli: partial purification and some properties. Journal of Biological Chemistry 218, 97-106.

Wegener, W. S., Reeves, H. C. \& AJl, S. J. (1967). Propionate oxidation in Escherichia coli. Archives of Biochemistry and Biophysics 121, 440-442.

WU, T. T. (1966). A model for three-point analysis of random general transduction. Genetics 54, 405-410. 